NBER WORKING PAPER SERIES

LEVERAGE AND ASSET PRICES:

AN EXPERIMENT.

Marco Cipriani

Ana Fostel

Daniel Houser

Working Paper 26701

http://www.nber.org/papers/w26701

\author{
NATIONAL BUREAU OF ECONOMIC RESEARCH \\ 1050 Massachusetts Avenue \\ Cambridge, MA 02138 \\ January 2020
}

We thank Cecilia Chen, David Hou, and Reed Orchinik for outstanding research assistance. We thank Douglas Gale, John Geanakoplos, Rosemary Nagel, and Andrew Schotter for very helpful comments. The views in this paper should not be interpreted as reflecting the views of the Federal Reserve Bank of New York, the Federal Reserve System, or the National Bureau of Economic Research. All errors are ours.

NBER working papers are circulated for discussion and comment purposes. They have not been peer-reviewed or been subject to the review by the NBER Board of Directors that accompanies official NBER publications.

(C) 2020 by Marco Cipriani, Ana Fostel, and Daniel Houser. All rights reserved. Short sections of text, not to exceed two paragraphs, may be quoted without explicit permission provided that full credit, including $\left({ }^{\circ}\right.$ notice, is given to the source. 
Leverage and Asset Prices: An Experiment.

Marco Cipriani, Ana Fostel, and Daniel Houser

NBER Working Paper No. 26701

January 2020

JEL No. A10,C90,D52,D53,G10

\section{ABSTRACT}

We develop a model of leverage that is amenable to laboratory implementation and gather experimental data. We compare two identical economies: in one economy, agents cannot borrow; in the other, they can leverage a risky asset to issue debt. Leverage increases asset prices in the laboratory. This increase is significant and quantitatively close to what theory predicts. Moreover, also as theory suggests, leverage allows gains from trade to be realized in the laboratory. Finally, the mechanism generating the price increase in the lab is due to the asset role as collateral, and different from what we would observe with a simple credit line or bigger cash endowments.

Marco Cipriani

Federal Reserve Bank of New York

33 Liberty Street

New York, NY 10045

marco.cipriani@ny.frb.org

Ana Fostel

Department of Economics

University of Virginia

Monroe Hall, Suite 222

Charlottesville, VA 22903

and NBER

anafostel@ virginia.edu
Daniel Houser

George Mason University

4400 University Drive, MSN 1B2

Fairfax, VA, 22030

dhouser@gmu.edu

A data appendix is available at http://www.nber.org/data-appendix/w26701 


\title{
Leverage and Asset Prices: An Experiment.
}

\author{
Marco Cipriani Ana Fostel Daniel Houser *
}

November, 2019

\begin{abstract}
We develop a model of leverage that is amenable to laboratory implementation and gather experimental data. We compare two identical economies: in one economy, agents cannot borrow; in the other, they can leverage a risky asset to issue debt. Leverage increases asset prices in the laboratory. This increase is significant and quantitatively close to what theory predicts. Moreover, also as theory suggests, leverage allows gains from trade to be realized in the laboratory. Finally, the mechanism generating the price increase in the lab is due to the asset role as collateral, and different from what we would observe with a simple credit line or bigger cash endowments.
\end{abstract}

Keywords: Leverage, Asset Pricing, Experimental Economics, Elicitation Method, Incomplete markets.

JEL Codes: A10, C90, D52, D53, G10

\section{Introduction}

The theoretical asset pricing literature has traditionally explained price fluctuations by focusing mainly on fundamentals (such as the interest rate, or the distribution of future cash flows). This approach has mostly disregarded the role that assets can play

*Marco Cipriani: Federal Reserve Bank of New York (email: marco.cipriani@ny.frb.org); Ana Fostel: University of Virginia and NBER (email: alf8p@virginia.edu). Daniel Houser: George Mason University (email: dhouser@gmu.edu). We thank Cecilia Chen, David Hou, and Reed Orchinik for outstanding research assistance. We thank Douglas Gale, John Geanakoplos, Rosemary Nagel, and Andrew Schotter for very helpful comments. The views in this paper should not be interpreted as reflecting the views of the Federal Reserve Bank of New York, or the Federal Reserve System. All errors are ours. 
as collateral. Over the last decade, after the 2008 financial crisis, there has a been an effort to understand the pricing implications of leverage. ${ }^{1}$ In particular, Fostel and Geanakoplos (2012b) show, in a general equilibrium model with endogenous collateral requirements, that leverage affects asset prices across equilibria. They first consider an economy in which borrowing cannot be sustained as the court system does not allow to seize collateral or enforce contracts. Second, they consider a financial innovation that allows for the use of assets as collateral to back non-contingent financial promise. Buying an asset while simultaneously selling a non-contingent promise is traditionally referred to as leveraging an asset. Fostel and Geanakoplos (2012b) show that, contrary to the spirit of Modigliani-Miller, leverage raises the price of the underlying collateral even if it has no effect on its total cash flows. ${ }^{2}$ Leverage also allows for the realization of gains from trade: when leverage is possible, assets are held to a greater extent by those agents who value them the most.

In this paper, we test the asset pricing implications of leverage in a controlled laboratory environment. To this purpose, we build a model of a financial economy with leverage similar to Fostel and Geanakoplos (2012b), yet simple enough to be implemented in a laboratory experiment. In our model, risk-neutral agents with heterogenous asset valuations trade a risky asset. We compare two identical economies: the $L$-economy, where agents can use the risky asset as collateral to issue debt, and the $N L$-economy, where they cannot. Theory predicts that the asset price and gains from trade are higher in the $L$-economy than in the $N L$-economy. In both economies, subjects with higher asset valuation are constrained. When leverage is not possible, they have to share the asset with agents valuing it less, thereby depressing its price. When leverage is possible, their demand for the asset shifts out: in equilibrium, they purchase a higher fraction of the asset supply, realizing gains from trade and pushing its price up.

In bringing the model to the laboratory, we face an important challenge: we want to be able to distinguish the effect of leverage on asset prices from more traditional

\footnotetext{
${ }^{1}$ See for instance, Acharya and Viswanathan (2011), Adrian and Shin (2010), Brumm et al. (2015), Brunnermeier and Pedersen (2009), Fostel and Geanakoplos (2008, 2012a, 2012b), Garleanu and Pedersen (2011), Geanakoplos (2010), Gromb and Vayanos (2002), Simsek (2013). Early contributions to the leverage literature were published before the crisis - see, for instance, Hindy (1994), Geanakoplos (1997 and 2003) - and only later became at the center of academic research.

${ }^{2}$ This is not only true when comparing asset prices across equilibria, but it also applies to differences in asset prices within the same equilibrium. See Fostel and Geanakoplos (2008) for a theoretical exposition on collateral value and deviations from the Law of One Price, and Cipriani et al. (2018) for experimental evidence.
} 
wealth effects such as a simple credit line or increases in cash endowments. In contrast to a uncollateralized credit line, the lower the price of the asset is, the more leverage relaxes agents' budget constraints. Because of this, the risky asset demand with leverage is more price elastic than with an uncollateralized credit line. With this in mind, we depart from the usual standard double auction (where we are only able to observe traded quantities and prices) and elicit each subject's whole demand or supply schedule. This is a novel methodology reminiscent, but different, from the "strategy method" often employed in experimental economics. Gathering data about the whole demand and supply schedules is crucial to understand the mechanism generating the results in the laboratory.

The laboratory results confirm the theory's main predictions. Leverage increases asset prices. This increase is significant and quantitatively very close to what theory predicts. That is, subjects in the laboratory are willing to pay more when the asset can be used as collateral. This occurs despite the fact that the asset's payoffs in both treatments are the same. Second, leverage allows gains from trade to be realized to a greater extent in the laboratory. When leverage is possible, agents who value the asset the most end up holding more of it. The increase in both prices and gains from trade in the $L$-treatment is due to the same mechanism described in the theory, an outward shift in demand from subjects with a higher asset valuation. Third, subjects' behavior in the laboratory is consistent with collateralized borrowing as opposed to a simple credit line or an increase in cash endowments. Finally, in contrast to the theory, aggregate demand shifts from the $N L$ - to the $L$-treatment despite subjects not being constrained in the $N L$-treatment; in the paper, we show how subject-level analysis helps understand these findings.

Our paper is related to a large and important literature in experimental finance, starting from Smith (1962), which tests asset pricing models in a controlled laboratory environment. King et al. (1983) first tested the effect of leverage on asset prices and found that leverage increases the frequency and the intensity of bubbles; in other words, the price increases more often and by more above the (expected) sum of future dividends. More recently, the effect of leverage on asset-price bubbles in a double auction market has been studied by Füllbrunn and Neugebauer (2012) and Gortner and Massenot (2018). In this experimental literature, the effect of leverage is similar, from an experimental standpoint, to that of an increase in cash endowments: see Caginalp et al. (1998), and Caginalp et al. (2001). ${ }^{3}$ In contrast, in our

\footnotetext{
${ }^{3}$ Our work is also related to that of Haruvy and Noussair (2006), who find that short sale
} 
paper, we study a different environment in which, due to market incompleteness and agents' heterogeneity, theory predicts that prices and the realization of gains from trade should increase if subjects are able to leverage; experimentally, the data confirm that leverage does in fact increase both prices and the realization of gains from trade. Our paper is related to Ciprani et al. (2018), but whereas they focus on the effect of leverage on asset prices within equilibrium and deviations from the Law of One Price, in this paper we focus on the effect of leverage across different economies. Finally, Cipriani et al. (2019) studies how collateral requirements and default endogenously arises in the laboratory, whereas in the present paper, we exogenously rule out default and focus only on the effect of collateral on asset prices.

The paper is organized as follows. Section 2 develops the theoretical model. Section 3 describes the experiment design and the experimental procedures. Section 4 presents the results. Section 5 concludes. All supplementary material is presented in the Appendix.

\section{Theory}

The purpose of this paper is to study the asset pricing implications of collateralized borrowing in a laboratory financial market. In order to do so, we study two different economies. First, the No-Leverage economy, from now on the $N L$-economy, where agents cannot use the asset as collateral, and hence borrowing is not possible. Second, the Leverage economy, from now on the L-economy, where agents are allowed to borrow using the asset as collateral.

\subsection{The NL-Economy}

We first consider an economy in which assets cannot be used as collateral. This may be the case, for example, under weak court systems that are unable to seize collateral. As a result, agents have no access to financial promises to transfer wealth across time and states, beyond cash an a risky physical asset.

constraints-a financial technology achieving the opposite effect than leverage-attenuates bubbles in the laboratory. 


\subsubsection{The Model}

There are two periods, $t=0,1$. At time 1 , there are two states of the nature, $s=H$ and $s=L$, (High and Low) which occur with probability $q$ and $1-q$. In the economy, there is a continuum of risk-neutral agents, of two different types $i=B, S$ (Buyers and Sellers).

There are two assets in the economy, cash and a risky asset $Y$ (from now on "the asset") with payoffs in units of cash. In state Low, the risky asset pays $D_{L}$, which is the same for all agent types, whereas in state High it pays more to Buyers than to Sellers, $D_{H}^{B}>D_{H}^{S}$. Nevertheless, for each type $i$, the payoff in the high state of the world is always higher than the payoff in the low state of the world, $D_{L}<D_{H}^{i}$. The difference in payoffs may be interpreted as Buyers and Sellers owning different technologies that affect the asset's productivity. ${ }^{4}$

At $t=0$, agents of type $i$ have an endowment of $m^{i}$ units of cash and of $a^{i}$ units of the asset. The payoff in units of cash in each state $s=H, L$ for investor $i$ is:

$$
\omega_{s}^{i}=w+D_{s}^{i} y
$$

where $w$ and $y$ denote cash and asset holdings at time 0 , and $D_{s}^{i} y$ denote total asset payoffs in state $s$. The expected payoff to agent of type $i$ is given by

$$
U^{i}=q \omega_{H}^{i}+(1-q) \omega_{L}^{i}
$$

Taking as given the asset price $p$, agents choose asset holdings $y$, and final cash holdings $w$ in order to maximize the payoff function (2) subject to their budget constraint:

$$
w+p y \leq m^{i}+p a^{i}
$$

An equilibrium in the $N L$-economy is given by asset price $p$, cash holdings $w$, and

\footnotetext{
${ }^{4}$ As in the theoretical literature, the presence of agents' heterogeneity is crucial for leverage to have an effect on trading activity and asset pricing. We model heterogeneity through heterogeneous asset payoffs since it makes the experimental implementation simpler. Differences in subjective probabilities, heterogenous asset payoffs, risk aversion, and wealth distribution all create the same effect of leverage on market allocative efficiency and asset prices; see for example Fostel and Geanakoplos (2008, 2012, 2014), Simsek (2013), Garleanu and Pedersen (2011).
} 
asset holdings $y$ such that the asset market clears and that agents maximize their payoff function (2) subject to the budget constraint (3).

\subsubsection{Parameter Values and Equilibrium Analysis.}

We calculate the equilibrium in the $N L$-economy. We solve the model for the first set of parameter values that we implement in the laboratory; we call this parameterization, presented in Table 1, the Bullish parameterization because state High is more likely than state Low.

Table 1: The Bullish Parameterization

\begin{tabular}{ccccccccc}
\hline Parameters & $D_{L}$ & $D_{H}^{B}$ & $D_{H}^{S}$ & $q$ & $m^{B}$ & $m^{S}$ & $a^{B}$ & $a^{S}$ \\
Values & 100 & 750 & 250 & 0.6 & 15,000 & 0 & 0 & 100 \\
\hline
\end{tabular}

Under this parameterization, the asset payoff in state Low is $D_{L}=100$; in state High is $D_{H}^{B}=750$ for the Buyers and $D_{H}^{S}=250$ for the Sellers. The probability of the state of the world being High is $q=0.6$. Buyers have initial cash endowments $m^{B}=15,000$, whereas Sellers have no cash. In contrast, Sellers have initial asset endowments, $a^{S}=100$, whereas Buyers have no asset endowment. Note that since Buyers have all the cash endowment and Sellers have all the asset endowment, Buyers are on the demand side and Sellers on the supply side of the asset market. ${ }^{5}$

Table 2 shows the equilibrium values for the $N L$-economy. ${ }^{6}$

Table 2: Equilibrium in the Bullish $N L$-economy.

\begin{tabular}{ccc}
\hline$p$ & \multicolumn{2}{c}{190} \\
\hline & Allocations and Final Payoffs \\
\cline { 2 - 3 } & Buyers & Sellers \\
\hline$y$ & 78.95 & 21.05 \\
$\varphi$ & 0 & 0 \\
$w$ & 0 & 15,000 \\
$w_{U}$ & 59,212 & 20,262 \\
$w_{D}$ & 7,895 & 17,105 \\
\hline
\end{tabular}

\footnotetext{
${ }^{5}$ For a more detailed discussion on parameters choice see Appendix II.

${ }^{6}$ See Appendix I for a description of the system of equations that characterizes the equilibrium.
} 
The equilibrium asset price is 190. In equilibrium, the Buyers use all their cash to buy all the assets they can afford; this happens because their expected value of the asset, $0.6(750)+0.4(100)=490$, is higher than the price, and the solution to their optimization problem is a corner solution. As a result, they invest their wealth of 15, 000 in buying 78.95 units at the price of 190, and their final cash holdings are zero.

In contrast, the solution to the Sellers' optimization problem is not a corner solution: at a price of 190 they are indifferent between holding cash and holding the asset, as their expected value equals the price, $0.6(250)+0.4(100)=190$. In equilibrium, they hold 21.05 units of the asset and 15,000 of cash.

The resulting equilibrium payoffs are 59,212 in state High and 7,895 in state Low for Buyers; 20, 262 in state High and 17, 105 in state Low for Sellers.

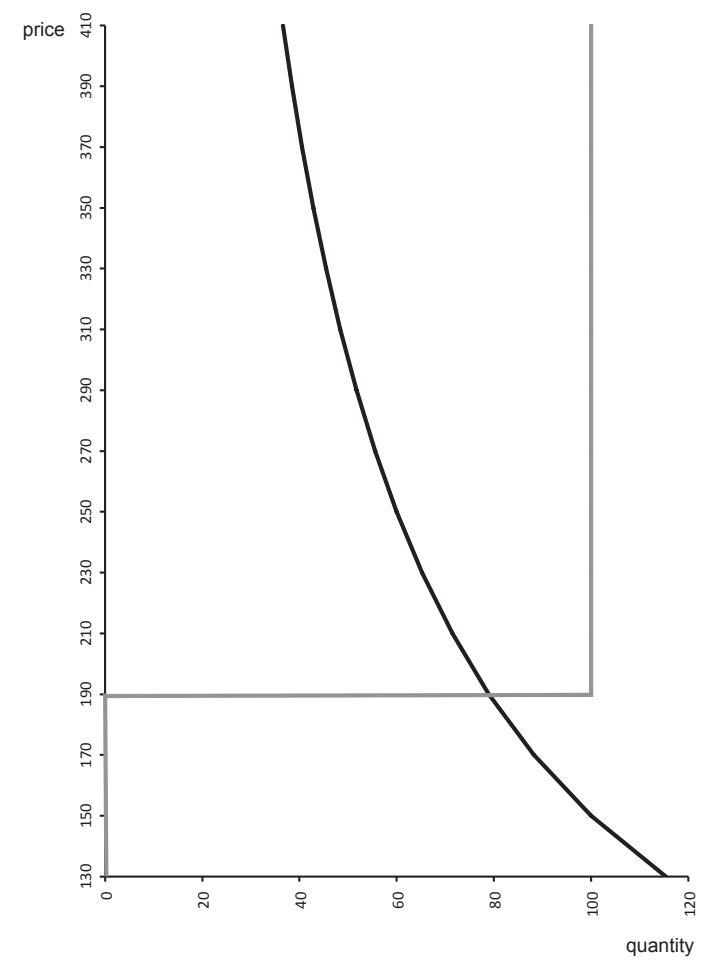

Figure 1: Supply (gray) and Demand (black) in the Bullish NL-economy.

Figure 1 shows the Sellers' supply and the Buyers' demand. The supply (gray line) is a step function that becomes horizontal at the Sellers' expected value (190). The 
demand (black line) is a decreasing function of the price, determined by the Buyers' budget constraint. ${ }^{7}$ Demand intersects supply at the horizontal segment of the supply schedule. As a result, in equilibrium, Sellers' expected value determines the price, whereas Buyers' budget constraint pins down the quantity traded.

\subsection{The L-Economy}

Consider the same environment as in the $N L$-economy, except that now we introduce the most basic financial innovation (arguably due to a more sophistical judicial system) which allows agents to use the risky asset as collateral to back a non-contingent financial promise. Buying the asset while simultaneously selling the non-contingent promise is called leveraging the asset.

\subsubsection{The Model}

In the $L$-economy agents can borrow from a bank using the asset $Y$ as collateral. Agents cannot borrow unless they post the asset as collateral. We assume that the maximum amount agents can borrow per unit of the asset is $D_{L}$, that is, the asset payoff in the low state. In other words, the minimum downpayment to purchase one unit of the asset is $p-D_{L}$. This condition guarantees that there can never be default in equilibrium, as the loan equals the asset payoff in state Low. ${ }^{8}$ This collateral constraint is sometimes referred to as Value at Risk equal to zero $(\operatorname{VaR}=0)$ and is widely used in the literature. ${ }^{9}$

In the $L$-economy, the payoff in units of cash in each state $s=H, L$ for investor $i$ is:

$$
\omega_{s}^{i}=w+D_{s}^{i} y-\varphi
$$

where $\varphi$ denotes total debt repayment. ${ }^{10}$

\footnotetext{
${ }^{7}$ The demand drops to zero when the price reaches the Buyers' expected value (490). In our parameterization, however, this region of the demand curve is irrelevant for the determination of equilibrium price and quantities.

${ }^{8}$ See Cipriani et. al (2019) for a study on collateral requirements and default in the laboratory.

${ }^{9}$ See for instance, Acharya and Viswanathan (2011), Adrian and Shin (2010), Brunnermeier and Pedersen (2009), Fostel and Geanakoplos (2008), Garleanu and Pedersen (2011).

${ }^{10}$ Since we are not modeling the credit market, we assume that the interest rate set by the bank is zero. That is, the amount borrowed at time $0, \varphi$, is also the amount to be repaid at time 1.
} 
Agents take the asset price $p$ as given and choose asset holdings $y$, cash holdings $w$, and borrowing $\varphi$ in order to maximize (2) subject to the budget constraint (5) and collateral constraint (6):

$$
\begin{gathered}
w+p y \leq m^{i}+p a^{i}+\varphi . \\
\varphi \leq D_{L} y
\end{gathered}
$$

The collateral constraint (6) states that an investor cannot borrow in excess of the maximum borrowing capacity associated to her total asset holdings.

An equilibrium in the $L$-economy is given by the asset price $p$, cash holdings $w$, asset holdings $y$, and borrowing $\varphi$ at $t=0$ such that the asset market clears and that agents maximize their payoff function (2) subject to constraints (5) and (6).

In the remainder of the section, we will show that the asset role as collateral has asset pricing implications.

\subsubsection{Parameter Values and Equilibrium Analysis.}

Table 3 shows the equilibrium values in the $L$-economy for the Bullish parameterization in Table $1 .^{11}$

Table 3: Equilibrium in the Bullish $L$-economy.

\begin{tabular}{ccc}
\hline$p$ & \multicolumn{2}{c}{250} \\
\hline & Allocations and Final Payoffs \\
\cline { 2 - 3 } & Buyers & Sellers \\
\hline$y$ & 100 & 0 \\
$\varphi$ & 10,000 & 0 \\
$w$ & 0 & 25,000 \\
$w_{U}$ & 65,000 & 25,000 \\
$w_{D}$ & 0 & 25,000 \\
\hline
\end{tabular}

The equilibrium asset price is 250. Since Buyers' expected value (490) is greater than the equilibrium price, they buy as many units of the risky asset as they can

\footnotetext{
${ }^{11}$ See Appendix I for a description of the system of equations that characterizes the equilibrium.
} 
afford using leverage. For each unit of the asset that they purchase, they borrow the maximum amount allowed (100 per unit of the asset) and pay a downpayment of 150 to cover the unit price of 250. Buyers use all their initial cash endowment to cover the total downpayment. Hence, they can afford to buy $\frac{15,000}{250-100}=100$, that is, all the asset supply in the economy. Since they borrow 100 per asset, the total borrowing is 10,000 .

The solution to Sellers' optimization problem is also a corner solution, since their expected value of the asset (190) is lower than the price. They sell all their endowment of the asset at a price of 250 and receive $100(250)=25,000$ in cash $(15,000$ received at time 0 as downpayment and 10,000 at time 1 when debt is repaid).

The resulting equilibrium payoffs are 65,000 in state High and 0 in state Low for Buyers; 25, 000 in both states for Sellers.

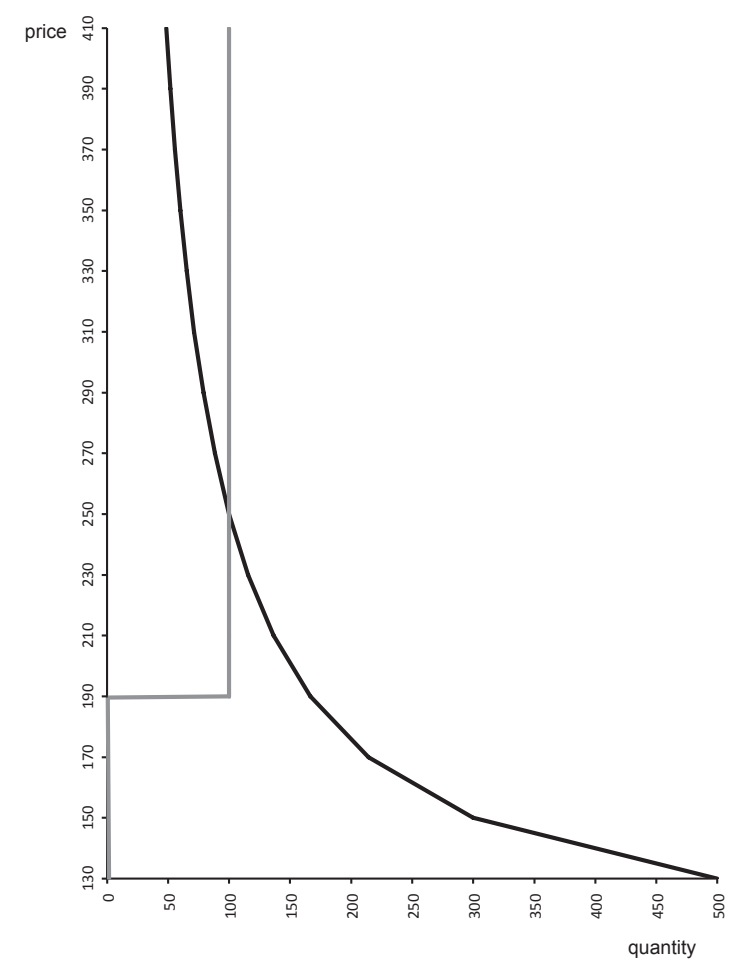

Figure 2: Supply (gray) and Demand (black) in the Bullish L-economy.

As before, it is instructive to characterize the equilibrium graphically. As Figure 2 shows, in the $L$-economy, the demand (black line) now intersects supply (gray line) 
at the vertical segment of the supply curve. Hence, Buyers buy all the assets in the economy and the equilibrium price is solely determined by demand.

\subsection{Leverage, Asset Prices, and Gains from Trade}

The main prediction of our model is that the equilibrium price is higher in the $L$ economy than in the $N L$-economy: the same asset (with the same payoff in all states of the word), when used as collateral to borrow money, has a higher price. Leverage increases asset prices.

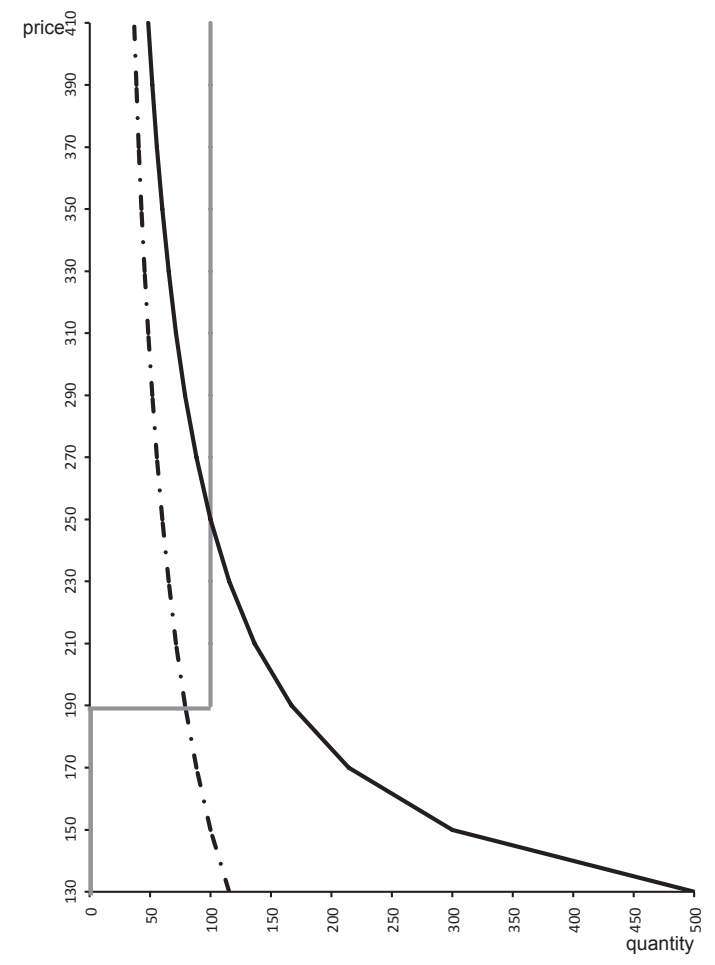

Figure 3: Supply (gray) and Demand ( $N L$-economy: dotted black; $L$-economy: solid black) in the Bullish Parameterization.

The effect of leverage on the equilibrium price can be seen in Figure 3, which combines Figures 1 and 2. The gray line is the supply function which is the same for both economies. The ability to borrow against the asset, however, affects demand: the demand in the $L$-economy (solid black) is always higher than in the $N L$-economy 
(dotted black). This can be seen from equations (3), (5) and (6). In both $L$ - and $N L$-economies, Buyers chose zero cash holdings provided that the price is less than 490 (their expected value). From their budget constraint (equation 3), we have that the demand in the $N L$-economy is given by $p=\frac{m^{i}}{y}$; whereas from equations (5) and (6) the demand in the $L$-economy is given by $\left(p-D_{L}\right)=\frac{m^{i}}{y}$, that is, there is an upward shift in demand. The shift takes place because the downpayment in the $L$-economy is reduced by the amount borrowed per unit of asset.

Note that the wedge between demands is the only factor generating the spread between prices in the two economies. Demand intersects supply at two different segments of the supply function. In the $N L$-economy, the intersection occurs where supply is flat, and as a result Buyers and Sellers share the asset, and Sellers' expectation determines its price. In the $L$-economy, the curves intersect where supply is vertical at 100; as a result, only Buyers hold the assets and their budget and borrowing constraints determine the price.

It is important to contrast the effect of collateralized borrowing from that of an uncollateralized credit line or an increase in cash endowment. In Figure 4, the black line is the demand schedule with collateralized borrowing that we discussed before. The gray line is the theoretical demand when Buyers are given an uncollateralized credit line of 10,000 (the same amount that agents borrow in the $L$-economy equilibrium); that is, it is the demand in a theoretical model in which agents have access to a credit line from the bank without the need of posting collateral. By construction, the two theoretical demands intersect at the equilibrium price of $250{ }^{12}$ However, the demand with collateralized borrowing is more elastic: as the price goes down, demand increases not only because Buyers can afford to purchase more units of the asset with their initial endowment of cash, but also because they can borrow more using the asset as collateral.

The effect of collateralized borrowing is also different from that of an increase in the cash endowment $m^{i}$. There are two reasons. An increase in the cash endowment moves the demand curve in the same way as the uncollateralized credit line analyzed before and as described in Figure 4 (i.e., the new demand is less elastic than that with collateralized borrowing). Additionally, with a cash increase Buyers' final payoff are higher, since there is no loan to be repaid in the final period.

\footnotetext{
${ }^{12}$ This is the case since at a price of 250 , agents borrow 10,000 in both cases and use all their purchasing power to buy assets.
} 


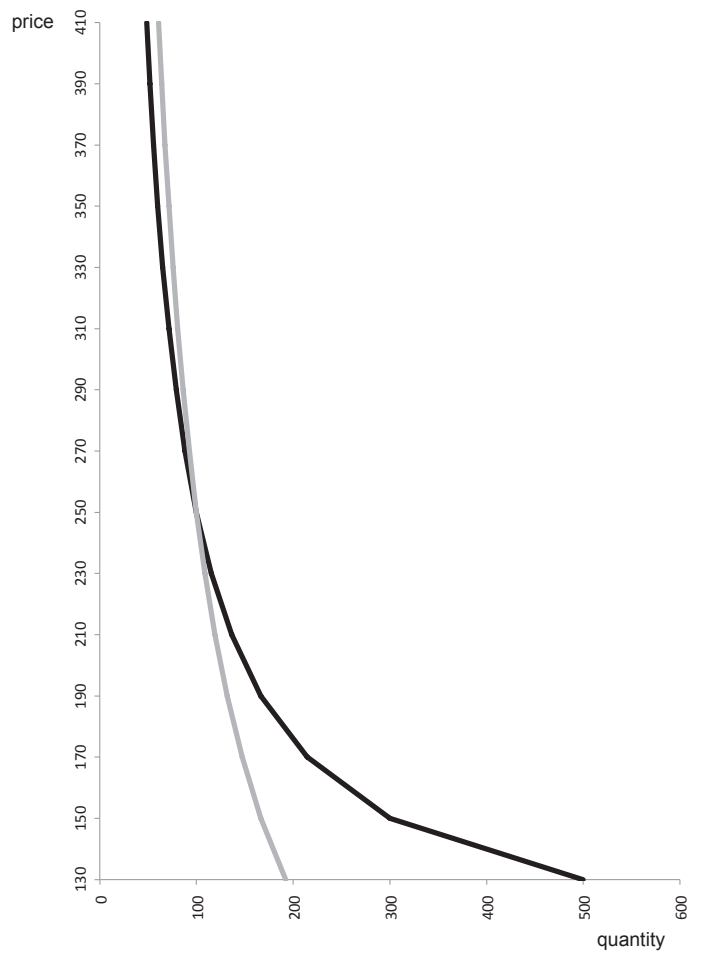

Figure 4: Demand under collateralized borrowing (black) and demand under credit line (gray).

Finally, another important prediction from the model, is that leverage allows gains from trade to be exploited to a full extent. In the $N L$-economy equilibrium, assets change hands from Sellers (who value the asset less) to Buyers (who value the asset more); thereby realizing some gains from trade in the economy. However, due to the Buyers' inability to borrow, gains from trade are not fully exploited: in equilibrium Sellers, who value the asset less than Buyers, hold a strictly positive quantity of the asset (21.05) and share it with the Buyers. In the $L$-economy, leverage allows Buyers to buy more units of the asset from Sellers, in fact Buyers hold the whole supply of the asset (100) and gains from trade are fully exploited in equilibrium. 


\subsection{The Bearish Parameterization}

When implementing the model in the laboratory, we consider a second parameterization in addition to the one presented in Table 1. The second parameterization is identical to the Bullish parameterization, except that $q$ is equals 0.4. We refer to this as the Bearish parameterization, as the probability of state High is now lower than that of state Low. This second parameterization shows that leverage increases asset prices regardless of agents' beliefs on the likelihood of state High, a proposition that we test in laboratory.

Table 4 shows the equilibrium outcomes when $q=0.4$ for both the $N L$ - and $L$ economy. Our two main theoretical predictions still hold for the Bearish parameterization: leverage increase asset prices and it enables the realization of gains from trade.

Table 4: Equilibrium in the Bearish Parameterization

\begin{tabular}{ccccc}
\hline & \multicolumn{2}{c}{$N L$-economy } & \multicolumn{2}{c}{$L$-economy } \\
\hline Price & \multicolumn{2}{c}{160} & \multicolumn{2}{c}{250} \\
\hline & Buyers & Sellers & Buyers & Sellers \\
\hline$y$ & 93.75 & 6.25 & 100 & 0 \\
$\varphi$ & 0 & 0 & 10,000 & 0 \\
$w$ & 0 & 15,000 & 0 & 25,000 \\
$u_{U}$ & 70,312 & 16,562 & 65,000 & 25,000 \\
$u_{D}$ & 9,375 & 15,625 & 0 & 25,000 \\
\hline
\end{tabular}

In the Bearish parameterization, the equilibrium regime is the same as the one described before: in the $N L$-economy the price is determined by Sellers, whereas in the $L$-economy it is determined by Buyers. The supply and demand curves for both the $L$ and $N L$-economies are shown in Figure 5 . In both the $L$ and the $N L$-economy, Buyers' demand does not shift with respect to the Bullish parameterization, as Buyers' behavior is determined by their budget and borrowing constraints (which are not affected by the probability of state High). ${ }^{13}$ In contrast, the Sellers' supply function shifts downward, as their expected value of the asset decreases with worse fundamentals. Because of this downshift in supply, the price in the $N L$-economy decreases. In

\footnotetext{
${ }^{13}$ Strictly speaking, this is true only for the region of prices below the Buyers' new expected value (360), which, however, is the relevant region for price determination given the Sellers' supply function.
} 
the $L$-economy the price is only determined by the Buyers because demand intersects supply in its vertical segment. Since demand does not change as $q$ changes, the price does not change either.

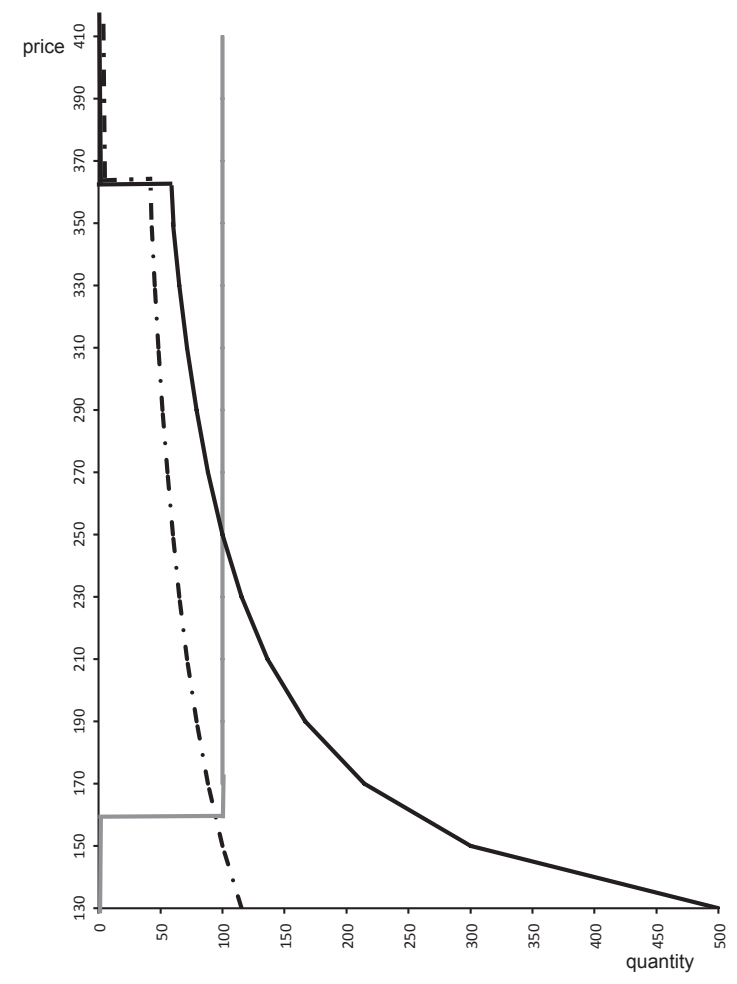

Figure 5: Supply (gray) and Demand (NL: dotted black; L: solid black) in the Bearish Economy.

\section{The Experiment}

\subsection{The Experiment Design}

The experiment was run at the Interdisciplinary Center for Economic Science, ICES, at George Mason University. We recruited subjects in all disciplines using the ICES online recruiting system. ${ }^{14}$ Subjects had no previous experience with the experiment.

\footnotetext{
${ }^{14}$ When the number of students willing to participate was larger than the number needed, we chose the subjects randomly in order to reduce the chance that the students in the experiment knew each other.
} 
The experiment was programmed and conducted with the software z-Tree. ${ }^{15}$

The experiment consisted of nine sessions. Twelve students participated in each session for a total of 108 students. Each session consisted of four treatments, corresponding to the four economies described in Section 2:

- The Bullish Parameterization in the No-Leverage Economy: the Bull-NL Treatment.

- The Bullish Parameterization in the Leverage-Economy: the Bull-L Treatment.

- The Bearish Parameterization in the No-Leverage Economy: the Bear-NL Treatment.

- The Bearish Parameterization in the Leverage-Economy: the Bear-L Treatment.

In each session, the same group of students played all four treatments, thus allowing us to study the difference in behavior across treatments with one-sample statistical techniques. For each of the nine sessions, we ran the experiment over two days; each day, subjects played two treatments. In order to control for possible order effects in the data, we ran four different treatment sequences as described in Table 5.

Table 5: Treatment Ordering

\begin{tabular}{l|ccccc}
\hline & \multicolumn{2}{|c|}{ Day 1} & \multicolumn{2}{c}{ Day 2} \\
\cline { 2 - 5 } & $1^{\text {st }}$ Treatment & $2^{\text {nd }}$ Treatment & $1^{\text {st }}$ Treatment & $2^{\text {nd }}$ Treatment \\
\hline Sequence 1 & Bull-NL & Bear-NL & Bull- $L$ & Bear- $L$ \\
Sequence 2 & Bear- $L$ & Bull- $L$ & Bear- $N L$ & Bull- $N L$ \\
Sequence 3 & Bull- $L$ & Bear- $L$ & Bull- $N L$ & Bear $-N L$ \\
Sequence 4 & Bear- $N L$ & Bull- $N L$ & Bear- $L$ & Bull- $L$ \\
\hline
\end{tabular}

In Sessions 1, 2 and 3, we ran Sequence 1; in Sessions 4 and 5 we ran Sequence 2; in Sessions 6 and 7 we ran Sequence 3; and in Sessions 8 and 9 we ran Sequence 4.

In each treatment of each session, we ran fifteen rounds of the same economy. The first four rounds of each treatment (both in treatments played on day one and in those played on day two) were used for practice, and did not determine students' payments.

\footnotetext{
${ }^{15}$ See Fischbacher (2007).
} 


\subsection{The Procedures}

We first describe the procedures for the Bull-NL treatment. Later we describe the procedures for the other treatments.

1. At the beginning of the experiment, we gave written instructions to all subjects. ${ }^{16}$ After reading the instructions aloud, we gave the subjects time to ask questions, which were answered in private.

2. All payoffs were denominated in an experimental currency called $E \$$. The risky asset was referred to as a "widget."

3. At the beginning of the round, each subject was randomly assigned to be either a Buyer or a Seller. In every round, there were six Buyers and six Sellers. Subjects could see their role in the left corner of their computer. Subjects had the same role in any given round of all four treatments they played: that is, if a subject was a Seller in the first round and a Buyer in the second round of the first treatment of the first day, then the subject was also a Seller in the first round and a Buyer in the second round of the other three subsequent treatments played in the session.

4. At the beginning of the round, each Buyer was given $\mathrm{E} \$ 15,000$ and each Seller was given 100 units of the asset.

5. Next, Buyers' demand and Sellers' supply were elicited by presenting them with a list of ten prices and asking them how many units of the asset they wanted to buy (Buyers) or sell (Sellers) at each price. For each of the 10 prices, Buyers were informed of the maximum number of assets that they could afford to buy. The computer mechanically enforced a weakly upward sloping supply, and a downward sloping demand. That is, if a Buyer demanded $x^{1}$ at a price $p^{1}$, she or he was only allowed to demand $x^{2} \leq x^{1}$ at a price $p^{2}>p^{1} \cdot{ }^{17}$

\footnotetext{
${ }^{16}$ The instructions and screenshots are in Appendix XI.

${ }^{17}$ Since the payoff is defined in terms of final cash only, no rational agent would choose an inverted demand or supply function. Moreover, without enforcing weak monotonicity, subjects' mistakes could create inversions in the aggregate demand or supply. As a result, there could be multiple prices for which the distance between aggregate demand and supply is low. Given our price-selection rule (bullet point 7), this would generate large changes in the equilibrium price for small changes in subjects' choices, thus making the equilibrium price less meaningful.
} 
6. The list of ten prices was taken from a pre-determined matrix and varied from round to round. Note that the matrix was the same (for each round) across sessions and treatments (i.e., we used the same matrix in the same round of each session and each treatment). We let prices vary slightly from round to round in order to avoid habituation. ${ }^{18}$

7. After all the subjects had made their choices, the computer calculated the price at which trading occurred. The price was determined by minimizing the excess supply over the ten prices. Subjects then learned about the price from the computer screen, and the trades were automatically realized. If excess supply was positive (negative) at the trade price, supply (demand) was proportionally reduced for all Buyers (Sellers).

8. After trading occurred, the state of the world was realized. An experimenter extracted a ball from an urn with 6 red balls and 4 green balls. If the extracted ball was red (green), the state of the world was High (Low). The outcome of the extraction was shown to all subjects.

9. After the state of the world was realized, subjects could see in the computer screen their final per-round payoff. In order to avoid a zero-payoff, a $E \$ 10,000$ bonus was paid to each subject at the end of each round.

10. After round 1 ended, a new round started. The session continued until all 15 rounds were played. Each round was independent from the previous one: subjects were not allowed to carry over endowments of cash or assets from one round to the next.

The procedures for the Bear-NL treatment were the same with the exception that the experimenter extracted the ball from an urn with 4 red balls and 6 green balls (so that the probability of state High was 40 percent). For the $L$ treatments (either Bull or Bear), we followed the same procedures described in points 1 to 10 , but now we allowed subjects to borrow. Subjects were explained in detail how borrowing worked: the maximum amount of borrowing allowed, its effect on subjects' budget constraint and the impact of loan repayment on their final payoff. ${ }^{19}$ During the experiment, Buyers' screenshots indicated how much they needed to borrow to afford a given number of assets at a given price. More precisely, for each price, Buyers were told

\footnotetext{
${ }^{18}$ The matrix of prices is shown in Appendix III.

${ }^{19}$ Instructions and screenshots for the $L$-treatments are in Appendix XI.
} 
how many assets they could afford a) if they did not borrow; b) if they borrowed the maximum of $E \$ 100$ per asset; c) if they borrowed only $E \$ 30$ per asset; and d) if they borrowed only $E \$ 60$ per asset. In the instructions, Buyers were told that this information was for reference only, and that they were not restricted to borrow the quantities indicated in the screen. ${ }^{20}$ Finally, after trading decisions were made, the screenshots indicated how much Buyers had borrowed and had to repay at the trading price determined by the computer.

Buyers were not allowed to borrow and keep a positive cash balance. This allowed us to simplify the choice problem facing the Buyers in that, for each price, they only had to choose the number of assets they wanted to buy. Given the complexity of the experiment, such simplification seemed sensible. ${ }^{21}$

After the 15 rounds of the first treatment were played, students were given the instructions for the second treatment, which was played right after on Day 1. The same group of students was gathered on the following day, Day 2, to play the two subsequent treatments. After the end of the fourth treatment, five rounds were extracted out of the last 11 rounds of each of the four treatments (as we mentioned before, the first four rounds were for learning purposes only). Payoffs were summed up and converted into US $\$$ at the rate of $E \$ 20,000$ per $\mathrm{US}^{22}{ }^{22}$

Our procedures are different from that of a standard double auction or of a call auction; in particular, we elicited the whole demand and supply schedule for each subject. This is a novel methodology reminiscent but different from the "strategy method:" whereas in the strategy method subjects choose an action conditional on all possible choices by the other subjects, in our experiment subjects choose an action conditional on the market price, which is the result of the choices of all subjects including themselves. ${ }^{23}$ Our elicitation method is close to that of Bias et al. (2014): whereas in their paper subjects choose from two predetermined demand and two predetermined

\footnotetext{
${ }^{20}$ The data do not show any discreetness in subjects' borrowing behavior: borrowing exactly 100, 30 or 60 was not very frequent.

${ }^{21}$ Furthermore, not allowing subjects to maintain positive cash balances while borrowing, if anything, reduces the amount borrowed; this works against finding significant differences in allocations and prices between the $N L$ - and $L$-economies.

${ }^{22}$ Due to a minor programming error in the z-tree code, earnings ("final cash") of Buyers who did not borrow in the $L$-treatments were under-reported as a proportion of per-round earnings by an average of 0.0013 , which corresponds to $\$ 0.002$. This minor miscalculation was evidently invisible to subjects, as no subject mentioned this small reduction in experimental earnings.

${ }^{23}$ Note that the price is an equilibrium outcome and not a node in a game. In contrast, in the the strategy method, subjects choose an action for all the nodes in the game where they may be called upon to act.
} 
supply schedules, in our experiment subjects construct their own demand and supply schedules by choosing quantities from a grid of prices. As we explain in Section 4, having information about the whole demand and supply schedules is crucial to understand the mechanism generating the results in the laboratory.

\section{Results}

\subsection{Leverage and Asset Prices}

We start by analyzing the experimental results, comparing the $N L$ and $L$ treatments under both the Bullish and the Bearish parameterizations. ${ }^{24}$ Under both parameterizations, the main prediction of the theory was confirmed in the laboratory: leverage increases asset prices. ${ }^{25}$

Tables $6 a$ and $6 b$ show for the Bullish and the Bearish parameterizations the average trade prices across the nine sessions of the experiment and in each session separately.

Table 6a: Average Trade Prices in the Bullish Parameterization

\begin{tabular}{ccccccccccc}
\hline & Average & S1 & S2 & S3 & S4 & S5 & S6 & S7 & S8 & S9 \\
\hline NL & 221 & 213 & 210 & 219 & 210 & 228 & 214 & 225 & 233 & 239 \\
$L$ & 262 & 241 & 263 & 260 & 241 & 263 & 258 & 277 & 274 & 277 \\
Spread & 41 & 28 & 53 & 41 & 31 & 35 & 44 & 52 & 41 & 38 \\
\hline
\end{tabular}

Table 6b: Average Trade Prices in the Bearish Parameterization

\begin{tabular}{ccccccccccc}
\hline & Average & S1 & S2 & S3 & S4 & S5 & S6 & S7 & S8 & S9 \\
\hline$N L$ & 192 & 182 & 187 & 203 & 195 & 175 & 206 & 180 & 204 & 197 \\
$L$ & 231 & 228 & 236 & 230 & 230 & 227 & 239 & 252 & 236 & 202 \\
Spread & 39 & 46 & 49 & 27 & 35 & 52 & 33 & 72 & 32 & 5 \\
\hline
\end{tabular}

\footnotetext{
${ }^{24}$ As explained in Section 3, subjects were paid only on their earnings in the last 11 rounds. Therefore, in the analysis, we restrict ourselves to the last 11 rounds of data. The results for all 15 rounds are reported in Appendix IV, and are in line with those reported here.

${ }^{25}$ This is consistent with the empirical finding in Cipriani et al. (2018) of positive collateral values in the laboratory.
} 
As theory predicts, the average trade price is higher in the $L$ than in the $N L$ treatment in each session, with an average spread across sessions of 39 (in the Bull treatments) and 41 (in the Bearish treatments). The increase in prices between the $N L$ - and $L$-treatment occurs in approximately 75 percent of the rounds of the experiment (see Appendix V). It is important to remark that under both parameterizations, the difference in prices is statistically significant (Wilcoxon test: $p$-value $=0.00$ in both parameterizations) and robust to order effects. ${ }^{26}$ As predicted by the theory, leverage increases asset prices regardless of subjects' "bullishness" (the probability they attach to the high state of the world).

\subsection{Leverage and Gains from Trade}

As predicted by the theory, as we move from the $N L$ - to the $L$-treatment, the quantity traded increases; that is, a larger number of assets is sold by the Sellers to the Buyers. As Tables $7 a$ and $7 b$ indicate, the average quantity traded per subject increases from 53 to 68 assets in the Bullish parameterization and from 56 to 68 in the Bearish one, a difference that is statistically significant (Wilcoxon test, $p$-value $=0.00$ in both parameterizations) and robust to order effects. ${ }^{27}$ The extent to which assets flow from Buyers to Sellers does not depend on subjects' "bullishness," in accordance to the theory's predictions.

Because of the increase in trading activity, gains from trade are realized to a further extent when leverage is allowed: for instance, in the Bullish parameterization, the sum of Buyers' and Sellers' payoffs increase from the $N L$ - to the $L$-economy on average by $(68-53)(500)(0.6)=4,500$. Note also that the increase in quantity traded between the $N L$ - and $L$ treatment occurs in approximately 90 percent of the rounds of the experiment (see Appendix V).

Table 7a: Per-Subject Average Quantity Traded in the Bullish Parameterization

\footnotetext{
${ }^{26}$ We test for differences prices with both non-parametric and parametric tests; additionally, the parametric tests allow us to study the robustness of our results to order effects and to study learning across rounds. Both order-effect and round dummies are not significant. See Appendix VII for a discussion.

${ }^{27}$ We test for differences in quantities with both non-parametric and parametric tests; additionally, the parametric tests allow us to study the robustness of our results to order effects and to study learning across rounds. Both order-effect and round dummies are not significant. See Appendix VII for a discussion.
} 


\begin{tabular}{ccccccccccc}
\hline & Average & S1 & S2 & S3 & S4 & S5 & S6 & S7 & S8 & S9 \\
\hline$N L$ & 53 & 57 & 46 & 63 & 64 & 49 & 54 & 52 & 44 & 49 \\
$L$ & 68 & 75 & 59 & 70 & 76 & 66 & 72 & 60 & 69 & 65 \\
\hline
\end{tabular}

Table 7b: Per-Subject Average Quantity Traded in the Bearish Parameterization

\begin{tabular}{ccccccccccc}
\hline & Average & S1 & S2 & S3 & S4 & S5 & S6 & S7 & S8 & S9 \\
\hline$N L$ & 56 & 49 & 56 & 62 & 66 & 61 & 51 & 46 & 54 & 56 \\
$L$ & 68 & 76 & 61 & 76 & 81 & 74 & 69 & 62 & 64 & 53 \\
\hline
\end{tabular}

\subsection{Empirical Aggregate Supply and Demand}

Are the experimental results described above driven by the very same forces that drive their theoretical counterparts? We can confirm that this is the case by analyzing the behavior of the demand and supply curves in the laboratory. This is precisely why, in the experimental design, we elicited from the subjects the whole demand and supply schedules.

The left panel in Figure 6 shows, for the Bullish parameterization, the empirical demand and supply in the $N L$ - and $L$-treatments. ${ }^{28}$ The empirical demand in the $L$-treatment (dotted-black line) shifts rightwards with respect to that of the $N L$ treatment (solid-black line), as subjects are allowed to leverage the asset. The shift is statistically significant (Wilcoxon test: $p$-value $=0.00$ ). ${ }^{29}$ As theory predicts (see Figure 3 in Section 2), this rightward shift in demand is what generates the spread between the prices in the $N L$ and $L$-treatments, as well as the increase in the quantities traded.

Also in accordance to the theory, the ability to leverage does not have an effect on the supply: the empirical supply in the $L$-treatment overlaps with that in the $N L$ treatment, and as a result there is no statistically significant shift in supply between treatments (Wilcoxon test: $p$-value $=0.42$ ). Incidentally, this is a good check that

\footnotetext{
${ }^{28}$ The empirical demand is computed as the average demand across subjects and rounds at a given price. That is, it must be interpreted as the demand per Buyer. Moreover, since in each round we slightly perturb the prices for which we elicit quantities demanded, in building the demand schedules we group prices in bins of size 20. Similar observations apply to the empirical supply curves.

${ }^{29}$ We test for shifts in the demand and supply curves with both non-parametric and parametric tests; additionally, the parametric tests allow us to study the robustness of our results to order effects. See Appendix VIII for a discussion.
} 
subjects understood the experiment since the problem that Sellers face is the same in the two treatments.
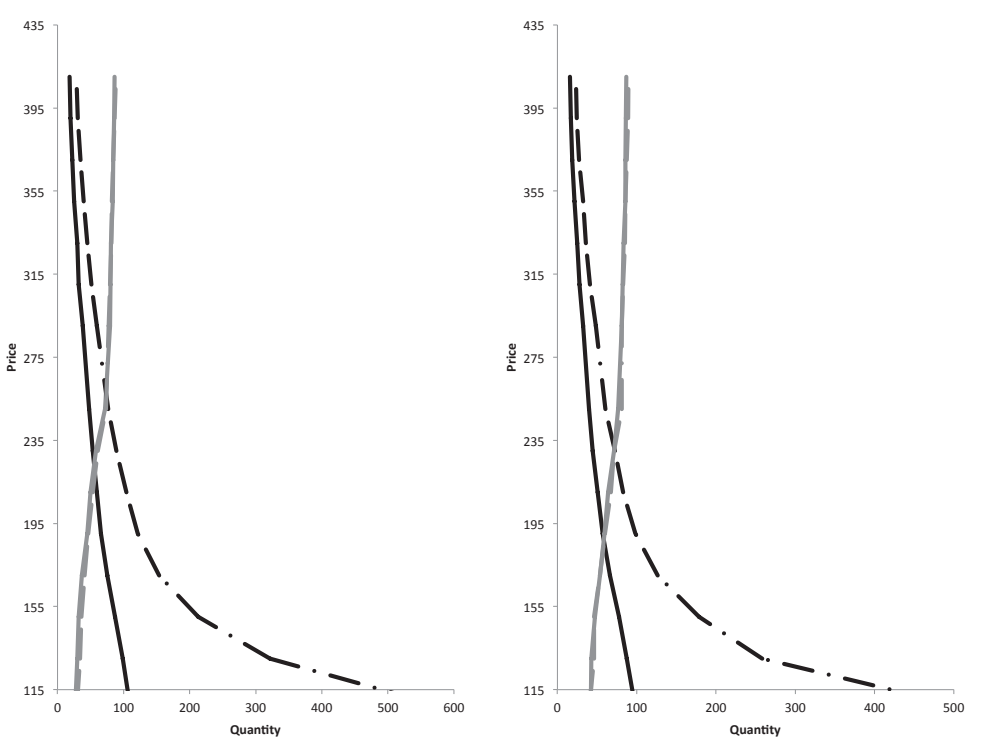

Figure 6: Left Panel: Supply (gray) and Demand (black) in the Bull-NL treatment (solid) and in Bull- $L$ treatment (dotted). Right Panel: Supply (gray) and Demand (black) in the Bear-NL treatment (solid) and in Bear- $L$ treatment (dotted).

Note also that subjects' behavior is consistent with collateralized borrowing as opposed to a simple credit line or an increase in cash endowments. Figure 7 compares, for the Bullish parameterization, the empirical demand in the $L$-treatment (dotted black) with the two different theoretical demand curves as presented in Figure 4 in Section 2. The solid black line is the demand under collateralized borrowing. The gray solid line is the theoretical demand when Buyers are given an uncollateralized credit line; that is, it is the demand in a theoretical model in which agents have access to a credit line from the bank of $E \$ 10,000$ without the need of posting collateral. As explained in Section 2, the two theoretical demands intersect at the equilibrium price of 250, since, at this price, the amount borrowed is $E \$ 10,000$, but they diverge as the price decreases. As Figure 7 shows, subjects' demand in the laboratory resembles the collateralized demand more closely than the credit-line demand. In particular, if subjects wanted to borrow a fixed amount their demand should be relatively vertical (as the theoretical demand with a credit line is). In contrast, the empirical demand is very elastic for low enough prices (as it is in the $L$-economy model): in the labora- 
tory as the price goes down subjects demand more, exploiting the collateral capacity of the assets.

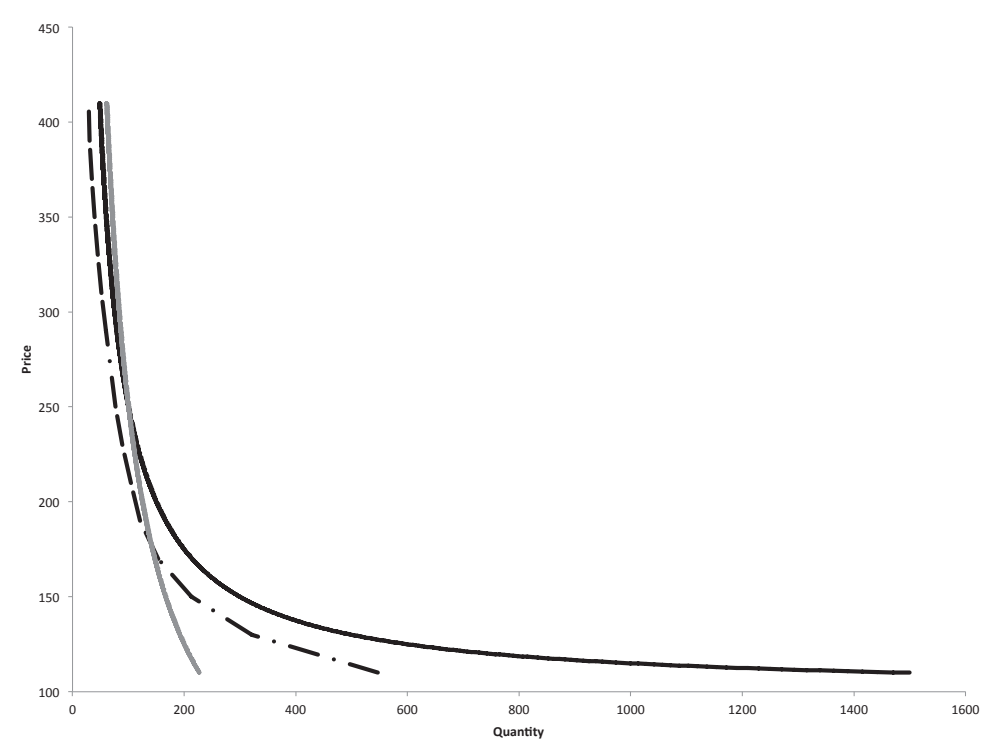

Figure 7: Experimental Demand (dotted black), Theoretical Demand (solid black) and Theoretical Demand with a Credit Line (solid gray) in the Bull- $L$ Treatment.

We can also check whether the mechanisms are in line with theory by looking at the behavior of aggregate curves across the two parameterizations, the Bullish (where $q$ equals 0.6) and the Bearish (where $q$ equals 0.4 ).

The left panel of Figure 8 shows the empirical supply curves (both in the $L$ and in $N L$-treatment); whereas the right panel shows the empirical demand curves. Note that the last three observations made for the Bull parameterization hold in the Bear parameterization as well. Moreover, as predicted by theory, supply shifts rightward (Wilcoxon test: $p$-value 0.00) as we move from the Bullish to the Bearish parameterization, reflecting the decrease in the asset's expected value, and therefore, Sellers' willingness to hold it.

\subsection{Deviations from Theory}

Although the experimental results are in line with the model's main predictions and the mechanisms generating them, there are two main deviations from the theory. 

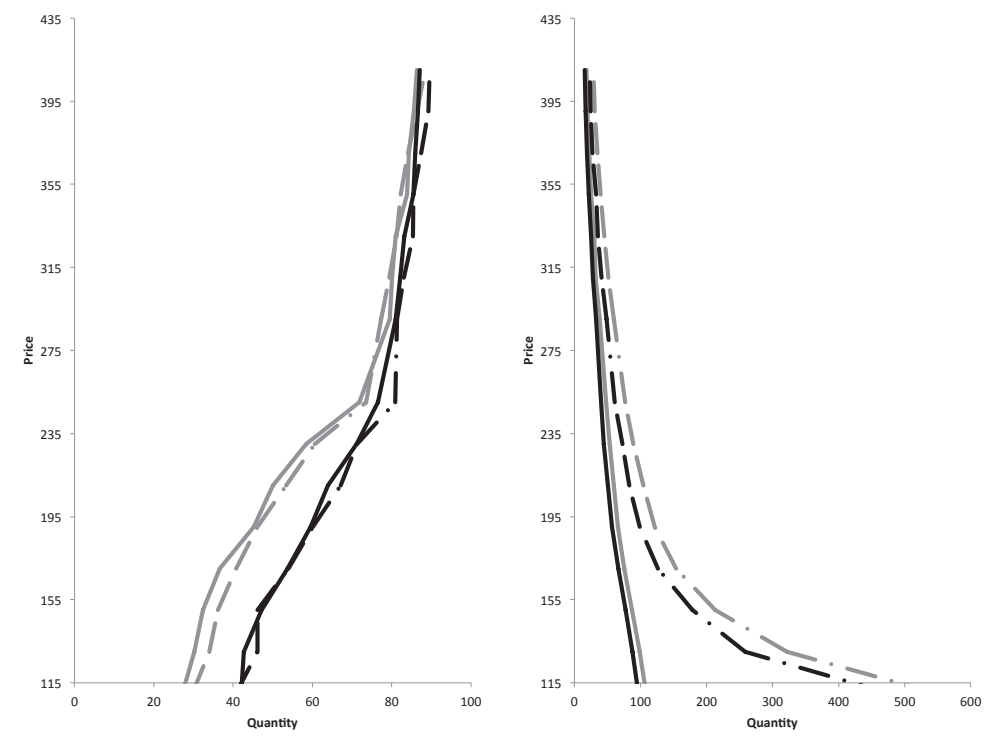

Figure 8: Left Panel: Empirical supply curves in the Bull (gray) and Bear (black) Parameterization. Right Panel: Empirical demand curves in the Bull (gray) and Bear (black) Parameterization. Solid lines refer to the $N L$-treatments; dotted lines to the $L$-treatments.

First, although the price of the asset increases from the $N L$ - to the $L$-treatment, in the $N L$-treatment prices in the laboratory are consistently above those predicted by the theory (in contrast in the $L$-treatment prices hover around their theoretical counterparts). Second, quantities traded in the laboratory are always below the theoretical levels. Although quantities traded increase from the $N L$ - to the $L$-treatment, Buyers always hold fewer assets than predicted by theory and in the $L$-treatment do not hold all the assets in the economy (on average only 68 instead of 100). As a result, the increase in the expected payoffs for Sellers and Buyers when leverage is allowed (that is, the realization of gains from trade) is lower than theory predicts.

As before, we will try to gain insight on these deviations by looking at subjects' demand and supply schedules, and comparing them to their theoretical counterparts.

First, in both economies, the empirical demand is to the left of the theoretical one; the difference between the two curves is statistically significant ( $p$-value: 0.00). ${ }^{30}$ The left panel in Figure 9 shows, for the Bullish parameterization, the experimental

\footnotetext{
${ }^{30}$ Statistical tests on the relative positions of empirical demand curves with respect to their theoretical counterparts are discussed and reported in Appendix IX.
} 

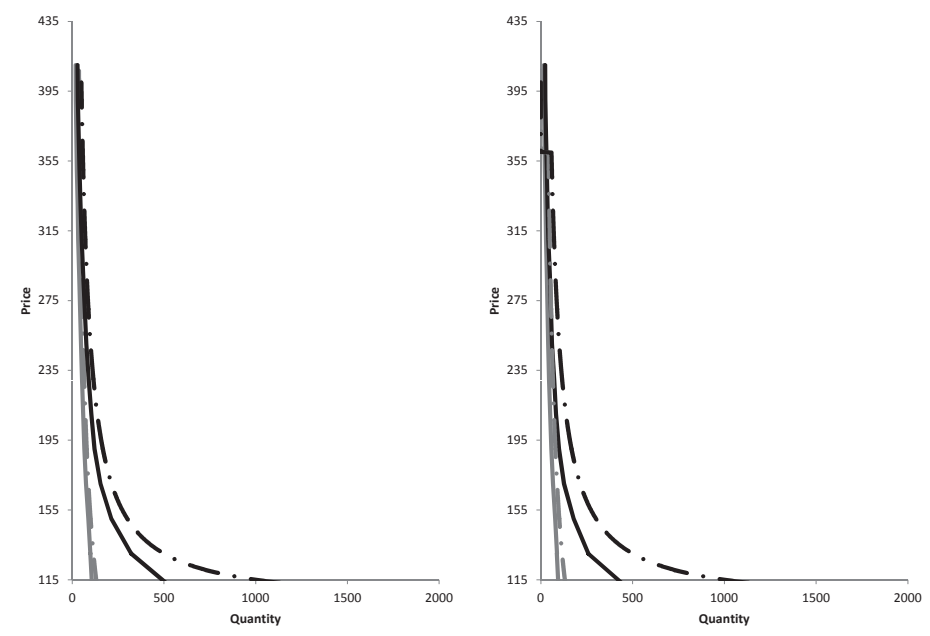

Figure 9: Left Panel: Experimental (solid) and Theoretical Demand (dotted) in the Bull-NL treatment (gray) and Bull- $L$ treatment (black). Right Panel: Experimental (solid) and Theoretical Demand (dotted) in the Bear-NL treatment (gray) and Bear$L$ treatment (black).

demands (solid line) and their theoretical counterparts (dashed lines) in both $N L$ and $L$-economies. In particular, in the $N L$-treatment (gray lines), Buyers' demand is not determined by the budget constraint as theory predicts. Indeed, as column 1 of Table $8 a$ shows, in the Bullish parameterization Buyers' average final cash holdings-which theoretically should be zero-are on average around $E \$ 3,340$ (out of an initial endowment of $E \$ 15,000)$.

Table 8a: Buyers' Final Cash Holdings and Borrowing in the Bullish Parameterization

\begin{tabular}{ccc}
\hline & Final Cash & Borrowing per Asset \\
\hline$N L$ & 3,340 & - \\
$L$ & 1,321 & 48 \\
\hline
\end{tabular}

Table 8b: Buyers' Final Cash Holdings and Borrowing in the Bearish Parameterization 


\begin{tabular}{ccc}
\hline & Final Cash & Borrowing per Asset \\
\hline$N L$ & 4,313 & - \\
$L$ & 2,605 & 35 \\
\hline
\end{tabular}

As Figure 9 shows, also in the $L$-treatment the empirical demand is to the left of its theoretical counterpart. That is, subjects do not exhaust all the collateral capacity of the assets. Indeed, Table $8 a$ shows that Buyers borrow on average $E \$ 48$ per asset, whereas in the theoretical equilibrium they borrow $E \$ 100$. Moreover, as the figure shows, the distance between the theoretical and the empirical demand is larger in the $L$-treatment than in the $N L$-treatment. That is, the shift in aggregate demand is smaller than predicted by the theory, thus explaining why in the laboratory the spread between $N L$ and $L$ prices is smaller. Similar remarks apply to the Bearish parameterization (see right panel of Figure 9 and Table $8 b$ ).

Moreover, Buyers' demand curves in both the $N L$ and the $L$-treatment shift significantly (Wilcoxon test: $p$-value 0.00) ${ }^{31}$ when we move from the Bullish to the Bearish parameterization. This is consistent with the fact that in the laboratory aggregate demand is not determined by subjects' budget constraint (as it is in the theory). Because demand shifts as we move from the Bullish to the Bearish parameterization, trade prices decrease both in the $L$ and in the $N L$-treatments (see Table $6 \mathrm{~b}$ ).

Let us now focus on the behavior of the aggregate supply schedules submitted by subjects, when playing the role of Sellers. As the left panel of Figure 8 shows, the curve is a smooth version of the theoretical one. According to the model, Sellers should sell 0 assets at a price below their expected value ( $E \$ 190$ in the Bullish parameterization, and $E \$ 160$ in the Bearish one), and sell all their holdings, 100, at a price above their expected value. Instead, under both parameterizations, in the experiment Sellers offer positive quantities for prices below their expected value (i.e., the empirical supply is to the right of the theoretical one), and supply less than 100 units for prices above their expected value (i.e., the empirical supply is to the left of the theoretical one). The smooth behavior of the empirical supply is a reason why, in the experiment, the price is higher than theory predicts. The departure of the empirical supply from the theoretical one has a much stronger effect on the equilibrium price of the $N L$-treatment than on that of the $L$-treatment; the reason is that whereas in the $L$-treatment theoretical demand meets supply where the supply

\footnotetext{
${ }^{31}$ Statistical tests on the shifts of demand and supply curves across all treatments are discussed and reported in Appendix VIII.
} 
is vertical, in the $N L$-treatment demand and supply meet in the perfectly elastic section of the theoretical supply curve. As a result, whereas in the $L$-treatment the average price is very close to its theoretical counterpart (e.g., 262 vs. 250 in the $L$-Bullish-economy), the equilibrium price in the $N L$-treatment is much higher than the theoretical one (221 vs. 190 in the $N L$-Bullish treatment).

Finally, the fact that the empirical aggregate demand is to the left and that the empirical supply is a smooth version of the theoretical one explains why quantities traded per subject (53 in the Bull-NL and 68 in the Bull- $L$ treatment) are lower than what theory predicts (78 and 100 respectively). As a result, in the laboratory, gains from trade are realized to a lower extent than theory predicts. Similar remarks apply to the Bearish parameterization (see right panel of Figure 9 and Table $8 b$ ).

\subsection{Individual-Level Analysis}

In this section, we shed light into the empirical results described so far by looking closer at subjects' individual behavior.

In Sections 4.3 and 4.4, we show that the empirical demand shifts between the $N L$ and the $L$-treatment. This rightward shift in demand, although in agreement with the theoretical predictions, is somewhat surprising given subjects' behavior in the laboratory. As we mentioned above, in the $N L$-treatment, the demand curve is not determined by the Buyers' budget constraint, that is, Buyers are not spending all their cash endowments. In such circumstances, one would expect that, allowing subjects to leverage should not affect their behavior; instead, we observe it does. ${ }^{32}$

Table 9: Buyers' Final Cash Holdings in the NL-Treatments

\begin{tabular}{cccccccc}
\hline Percentage of Subjects & 5 & 20 & 25 & 50 & 75 & 80 & 95 \\
Final Cash Holdings Lower than & 662 & 1,462 & 1,574 & 2,800 & 5,512 & 5,835 & 9,373 \\
\hline
\end{tabular}

Table 10: Buyers' Borrowing Per Asset in the $L$-Treatments

\footnotetext{
${ }^{32}$ In Appendix VI, we show that, under very general conditions on subjects' payoff functions, if a Buyer chooses not to use all the available cash in the $N L$-economy, the Buyer should choose not to borrow in the $L$-economy.
} 


\begin{tabular}{cccccccc}
\hline Percentage of Subjects & 5 & 20 & 25 & 50 & 75 & 80 & 95 \\
Borrowing Per Asset Lower than & 0 & 12.87 & 16.28 & 40.93 & 63.48 & 69.52 & 86.17 \\
\hline
\end{tabular}

The aggregate shift in demand could be the result of heterogeneity in subjects' choices. Table 9 shows individual cash holdings in the $N L$-treatment, jointly for the Bullish and Bearish parameterization. ${ }^{33}$ As the table shows, individual behavior is quite heterogeneous. On the one hand, 25 percent of subjects decide to keep approximately 10 percent or less of their initial cash, thus exhibiting a behavior that is close to theory (zero final cash holdings). On the other hand, 25 percent keep slightly more than one third of their initial cash.

Table 10 shows similar statistics for borrowing behavior in the $L$-treatments, jointly for the Bullish and Bearish parameterization. ${ }^{34}$ Individual behavior is also quite heterogeneous. On the one hand, 25 percent of subjects borrow very little, on average less than $E \$ 16.28$. On the other hand, there are subjects who do exploit the collateral capacity of the asset: 50 percent of subjects borrow on average more than 40.93, and 20 percent of subjects borrow on average more than 69.52 per asset.

The shift in aggregate demand can be explained by the heterogeneity described in Tables 9 and 10 if the subjects who do borrow in the $L$-treatments are primarily those who are close to their budget constraint in the $N L$-treatments. This is indeed what we find. Figure 10 shows, for each subject, the average percentage borrowing per asset in the $L$-treatment vs. the average final cash holdings in the $N L$-treatment. ${ }^{35}$ There is a clear negative association between the two variables: the closer subjects are to their budget constraint in the $N L$-treatment, the more they borrow in the $L$-treatment. ${ }^{36}$

In Sections 4.3 and 4.4, we also mention that the empirical supply is a smooth version of the theoretical one. The behavior of the aggregate supply cannot be reconciled with subjects having a uniform attitude toward risk: subjects supply a positive quantity of the asset for a price lower than the asset's expected value, but do not supply all their asset endowments for a price higher than the asset's expected value.

Figure 11 shows the histogram of the Sellers' individual average deviations from the

\footnotetext{
${ }^{33}$ For each subject, we compute the average final cash holdings in the $N L$-treatments across rounds, sessions and parameterizations. We report the quantiles of subjects' average cash holdings.

${ }^{34}$ For each subject, we compute the average borrowing per asset in the $L$-treatments across rounds, sessions and parameterizations. We report the quantiles of subjects' average borrowing per
} 


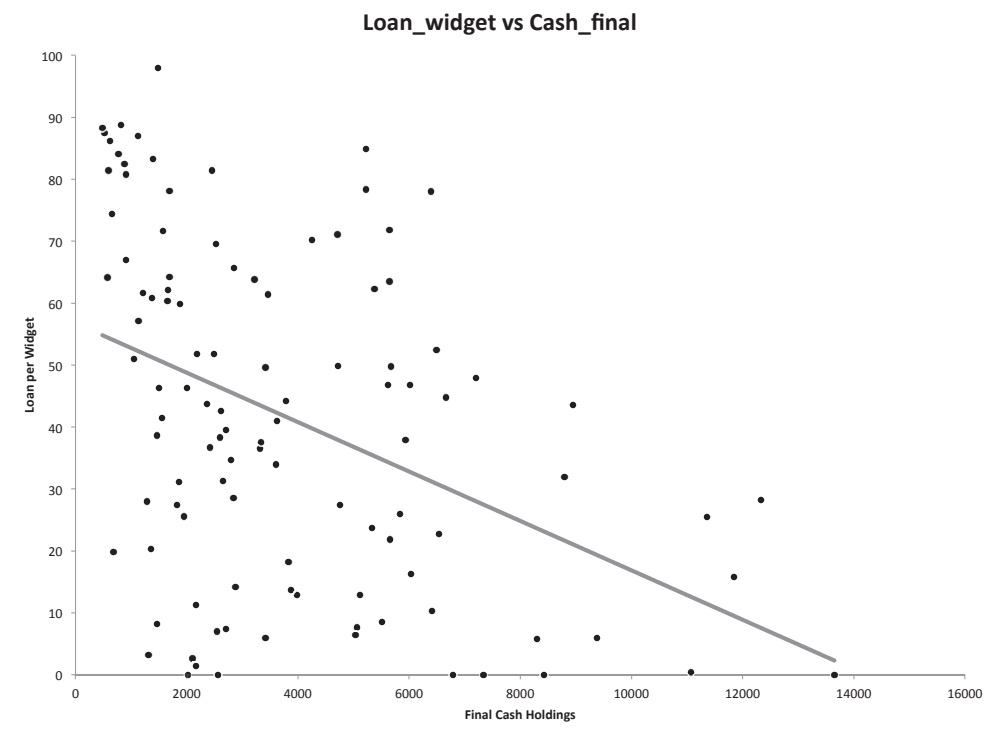

Figure 10: Scatter Plot of the Average Individual Percentage Borrowing Per Asset in the $L$-treatment over Final Cash Holding in the $N L$-treatment in both parameterizations.

theoretical supply across all prices and rounds. ${ }^{37}$ As the figure shows, almost 30 percent of the subjects deviate from the theoretical supply by less than 5 units; that is, their behavior is on average close to that predicted by theory. A small proportion of subjects (around 15 percent) supply on average 5 units or more than predicted by theory. On the other hand, a full 55 percent of subjects are selling on average at least 5 units less than predicted by theory, with around 20 percent supplying less than $25 .^{38}$ In other words, subjects' behavior when they act as Sellers is quite heterogeneous. As a result, when we aggregate subjects' supply choices in the empirical aggregate supply schedules of Figures 6 and 8, we obtain a smooth version of its theoretical counterpart.

\footnotetext{
asset.

${ }^{35}$ The scatter plot is built using data from both parameterizations.

${ }^{36}$ The results of the regression analysis are reported in Appendix X. A decrease in average final cash by $\mathrm{E} \$ 1,000$ increases borrowing per widget by 4 units; the coefficient is significant.

${ }^{37}$ The figure combines data from both the Bullish and the Bearish parameterizations.

${ }^{38}$ Note that the same subjects, who want to hold more assets than theory predicts, would not be able to do so when acting as a Buyer (because the optimal choice is on the budget and borrowing constraints, in both $L$ and $N L$-economies). Therefore, these subjects would not generate deviations of the aggregate demand curve with respect to the theoretical one.
} 


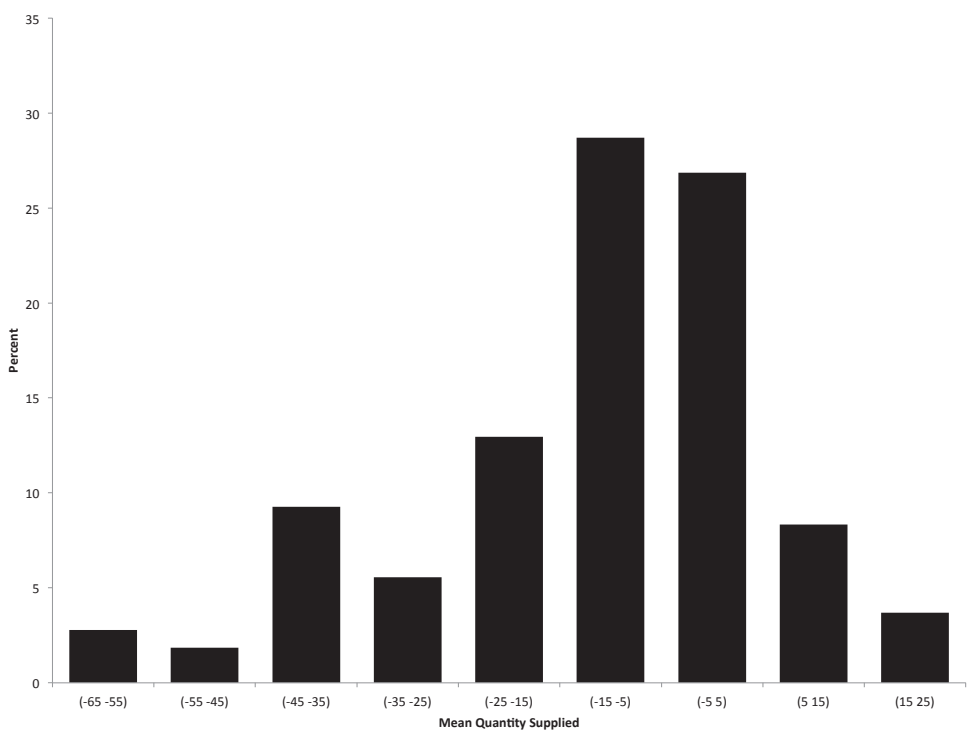

Figure 11: Histogram of Individual Supply Behavior. Horizontal axis: Average Deviation from Theoretical Supply. Vertical axis: Relative Frequency.

\section{Conclusion}

We study the implication of leverage (collateralized borrowing) on asset prices in a controlled laboratory environment. To this purpose, we develop a model of leverage that is amenable to laboratory implementation, and we gather experimental data.

We show that, in the laboratory financial market, the same asset when traded in two different environments, has a different price. In particular, when an asset can be used as a collateral its price is higher. Both the direction and the magnitude of the increase is in line with what theory suggests. Moreover, also as theory predicts, the higher price of the collateralized asset stems from a shift in demand, and this shift is observationally different from other shifts in demand generated by simple credit lines or higher cash endowments. Finally, leverage allows gains from trade to be realized in the laboratory; when leverage is possible, agents who value the asset the most end up holding more of it. 


\section{References}

Acharya, Viral and S. Viswanathan. 2011. "Leverage, Moral Hazard and Liquidity." Journal of Finance, 66, 99-138.

Adrian, Tobias and Hyun Shin. 2010. "Liquidity and Leverage." Journal of Financial Intermediation, 19 (3), 418-437.

Bias Bruno, Christophe Bisiere, and Sebastien Pouget. 2014. "Equilibrium discovery and preopening mechanisms in an experimental market." Management Science, 60(3), iv-vii, 541-804.

Brumm, Johannes, Michael Grill, Felix Kubler, Karl Schmedders. 2015. "Collateral requirements and asset prices." International Economic Review, 56(1), 1-25.

Brunnermeier, Markus, 2009. "Deciphering the Liquidity and Credit Crunch 20072008." Journal of Economic Perspectives, 23, 77-100.

Brunnermeier, Markus and Lasse Pedersen. 2009. "Market Liquidity and Funding Liquidity." Review of Financial Studies, 22(6), 2201-2238.

Caginalp, Gunduz, David Porter, and Vernon Smith. 1998. "Initial cash/asset ratio and asset prices: An experimental study." Economic Sciences, 95, 756-761.

Caginalp, Gunduz, David Porter, and Vernon Smith. 2001. "Financial Bubbles: Excess Cash, Momentum, and Incomplete Information." Journal of Psychology and Financial Markets, 2(2), 80-99.

Cipriani, Marco, Ana Fostel, and Daniel Houser. 2018. "Collateral Constraints and the Law of One Price: an Experiment." Journal of Finance, 73(8), 2757-2786.

Cipriani, Marco, Ana Fostel, and Daniel Houser. 2019. "Endogenous Leverage and Default in the Laboratory." NBER Working Paper, w26469.

Fischbacher, Urs. 2007. "z-Tree: Zurich toolbox for ready-made economic experiments." Experimental Economics 10, 171-178.

Fostel, Ana and John Geanakoplos. 2008. "Leverage Cycles and the Anxious Economy." American Economic Review, 98(4), 1211-1244.

Fostel, Ana and John Geanakoplos. 2012a. "Why Does Bad News Increase Volatility and Decrease Leverage." Journal of Economic Theory. 147(2): 501-525. 
Fostel, Ana and John Geanakoplos. 2012b. "Tranching, CDS and Asset Prices: How Financial Innovation can Cause Bubbles and Crashes." American Economic Journal: Macroeconomics. 2012, 4(1): 190-225.

Fostel, Ana and John Geanakoplos. 2014. "Endogenous Collateral Constrains and the Leverage Cycle." Annual Review of Economics. Vol. 6: 771-799

Füllbrunn, Sascha and Tibor Neugebauer. 2012. "Margin Trading Bans in Experimental Asset Markets." Jena Economic Research Papers, No. 2012,058

Garleanu, Nicolae and Lasse Pedersen. 2011. "Margin-Based Asset Pricing and Deviations from the Law of One Price." Review of Financial Studies, 24(6), 19802022 .

Geanakoplos, John. 1997. "Promises, Promises." In The Economy as an Evolving Complex System II, ed. W. Brian Arthur, Steven Durlauf, and David Lane, 285-320. Reading, MA: Addison-Wesley.

Geanakoplos, John. 2003. "Liquidity, Default, and Crashes: Endogenous Contracts in General Equilibrium." In Advances in Economics and Econometrics: Theory and Applications, Eighth World Conference,Vol. 2, 170-205. Econometric Society Monographs.

Geanakoplos, John. 2010. "The Leverage Cycle." NBER Macroeconomic Annual. $1-65$.

Gortner, Paul and Baptiste Massenot. 2018. "Macroprudential Policy in the Lab." SAFE Working Paper, 239.

Gorton, Gary, 2009. "The Subprime Panic." European Financial Management, 15(1), $10-46$.

Gromb, Dennis and Dimitri Vayanos. 2002. "Equilibrium and welfare in markets with financially constrained arbitrageurs." Journal of Financial Economics. 66,361407.

Haruvy, Ernan and Charles Noussair. 2006. "The Effect of Short-Selling on Bubbles and Crashes in Experimental Spot Asset Markets." Journal of Finance, 61, 11191157 .

Hindy, Ayman. 1994. "Viable Prices in Financial Markets with Solvency Constraints." Journal of Mathematical Economics, 24, 105-135. 
King, Ronald, Vernon Smith, Arlington Williams, and Mark Van Boening. 1993. "The Robustness of Bubbles and Crashes in Experimental Stock Markets." Nonlinear Dynamics and Evolutionary Economics, 183-200.

Kirchler, Michael, Jürgen Huber, and Thomas Stöckl. 2012."Thar she bursts - Reducing confusion reduces bubbles." American Economic Review, 102(2), 865-883.

Plott, Charles and Shyam Sunder. 1982. "Efficiency of Experimental Security Markets with Insider Information: An Application of Rational-Expectations Models." Journal of Political Economy, 90(4), 663-698.

Porter, David and Vernon Smith. 2003. "Stock Market Bubbles in the Laboratory." Journal of Behavioral Finance, 4(1), 7-20.

Simsek, Alp, 2013, "Belief disagreements and collateral constraints." Econometrica $81,1-53$.

Smith, Vernon. 1962. "An Experimental Study of Competitive Market Behavior." Journal of Political Economy, 70(2), 111-137.

Smith, Vernon, Gerry Suchanek, and Arlington Williams. 1988. "Bubbles, Crashes, and Endogenous Expectations in Experimental Spot Asset Markets." Econometrica, 56(5), 1119-1151. 